\title{
Kanca Ucu Tipinin Çelik Tel Donatılı Betonların Mekanik Özelliklerine
} Etkisi

\author{
Eyüp TAŞKAN ${ }^{1}$, Yunus GÜNDÜZ ${ }^{1}$, Yuşa ŞAHIN ${ }^{2 *}$ \\ ${ }^{1}$ Yozgat Bozok Üniversitesi, Fen Bilimleri Enstitüsü, Yozgat. \\ ${ }^{2}$ Yozgat Bozok Üniversitesi, Mühendislik Mimarlık Fakültesi, Inş̧aat Mühendisliği Bölümü, Yozgat.
*Sorumlu yazar e-posta: yusa.sahin@bozok.edu.tr eyup.taskan@hotmail.com
ORCID ID: https://orcid.org/0000-0002-3586-412X
ORCID ID: https://orcid.org/0000-0002-6649-6809
yunusgunduz_66@hotmail.com_ORCID ID: https://orcid.org/0000-0001-9740-0980

Geliş Tarihi: 21.12.2018; Kabul Tarihi: 01.10.2019

Öz

Beton içerisine katılan kısa kesilmiş çelik teller uzun yıllardır inşaat sektöründe kullanılmaktadır. Yarı gevrek bir malzeme olan betonun sünekliğini artırmak için en sık uygulamalardan bir tanesi beton içerisine kısa kesilmiş tellerin katılmasıdır. Tellerin beton karışımlarında kullanılmasıyla betonların çekme dayanımı, sünekliği ve tokluk değerleri başta olmak üzere diğer birçok özeliklerinde iyileşmeler

Anahtar kelimeler Beton; Çelik Tel; Kanca Ucu; Mekanik Özelikler;

Tokluk. görülmüştür. Tel miktarlarının, uzunluklarının, narinliklerinin, biçimlerinin ve tel dayanımlarının betonların mekanik özelliklerine etkileri birçok araştırmacı tarafından araştırılmıştır. Bununla birlikte, beton sektörünün intiyaçlarına bağlı olarak tel türleri ve tellerin geometrik özelliklerinde çeşitlilik artmıştır. Çelik tel kanca ucu tiplerindeki yenilikler bu çalışmanın konusunu oluşturmuştur. Çalışma kapsamında bir deneysel araştırma yürütülmüş ve kanca ucu tipleri farklı çelik teller farklı miktarlarda beton içerisine katılmıştır. Betonların basınç dayanımları ve elastisite modüleri ile yarmada çekme ve eğilme dayanımları gibi mekanik özellikleri belirlenerek kanca ucu tipinin etkisi ortaya konmuştur. Çelik tel kullanılmasıyla yarmada çekme dayanımlarında \%30,6 ve eğilme dayanımlarında \%71,9 oranlarında artışlar elde edilmiştir. Bu artışlar üzerinde tel kanca ucu tipinin etkisi görülmüştür.

\section{Effect of Type of Hooked-End on the Mechanical Properties of Steel Fiber Reinforced Concretes}

\begin{abstract}
Short cutted steel fibers are used in civil engineering structures for long time. Addition of steel fibers is one of the most used application with respect to increase the ductility of concrete which is a quasibrittle material. Especially, ductilities, tensile strengths, and toughnesses of concrete were increased by adding steel fibers in mixtures. Effect of amounts, lengths, aspect ratios, shapes and strengths of fibers were investigated in previous studies. However, type of steel fibers was varied depending on the expectations of concrete industry. Effect of type of hooked-end was subject of this study. An experimental research was conducted and 3 different types of hooked-ended steel fibers were added in concrete mixtures. Mechanical properties such as compressive strength and modulus of elasticity, splitting tensile and flexural strength were performed on SFRCs, and effect of type of hooked-ended steel fibers was revealed. By using steel fiber, $30.6 \%$ increase in splitting tensile and $71.9 \%$ increase in flexural strength were obtained. The effect of fiber hooked-end type was observed on these increases.
\end{abstract}

\section{Giriş}

Gevrek kırılma davranışı sergileyen çimento esaslı malzemelerde dayanımı arttırmak, çatlak oluşumunu engellemek gibi amaçlara yönelik olarak karışımlara metalik, sentetik, cam ve doğal (organik ve inorganik) lifler katılmaktadır. Yüksek mekanik özeliklere intiyaç duyulduğu koşullarda sıklıkla çelik teller tercih edilmektedir. Çelik tellerin çap, boy ve diğer geometrik özellikleri farklı 
olabildiği gibi karbon oranları da değiştirilerek farklı dayanıma sahip çelik teller üretilebilmektedir.

Çelik Tel Donatılı Betonlar (ÇTDB)'da, çelik tellerin etkisi çimento matrisi çatladıktan sonra görülmektedir (Taşdemir ve Bayramov 2002, Yoo et al. 2014, Boğa 2017). Ani göçme gibi tehlikeli durumların önlenmesinde kullanılacak olan yüksek enerji yutma kapasitesine sahip yüksek performanslı betonların üretilmesinde çelik tel kullanımı önemli bir yere sahiptir (Knapton 2003, Beddar 2004, Feng et al. 2014, Pajak and Ponikiewski 2017). Çelik tel donatılı betonların saha betonları, püskürtme beton uygulamaları ve tünel ve şev kaplamaları gibi yaygın kullanım sahaları bulunmaktadır. Bunların yanında endüstriyel zemin uygulamaları ve beton borular gibi zemine oturan elemanların üretiminde, geleneksel donatılı betonların yerine ÇTDB'ler tercih edilebilmektedir (Taşdemir vd. 2006).

Çelik tellerin ana görevi, çatlak yüzlerini köprüleyerek çatlağın açılmasını ve ilerlemesini kontrol etmektir. Köprüleme etkisinin başarılı olması genellikle telin yüzeyden sıyrılma mekanizmasına bağlıdır. Sıyrılma ise sadece tel ve çimento matrisi arasındaki bağın sağlamlığına bağlı olmayıp bunun yanında telin kanca ucu tip ve türü gibi özeliklerine de bağlıdır (Gündüz 2015, Uğur 2015, Taşkan 2017). Sıyrıma dayanımını arttırmak amacıyla mekanik olarak deforme edilmiş teller düz tellere kıyasla tercih edilmektedir (Banthia and Trottier 1994, Robins et al. 2002, Altun vd. 2007, Cunha et al. 2010, Soetens and Matthys 2014).

Bu çalışmada, kanca ucu tipi ve dayanımları farklı olan çelik tellerin beton karışımlarına çeşitli miktarlarda eklenmesiyle elde edilen ÇTDB'lerin mekanik özellikleri araştırılmıştır. Kanca ucu tipinin etkisi betonların tokluk ve eğilme dayanımı değerleri incelenmesiyle belirlenmiştir.

\section{Materyal ve Metot}

\subsection{Materyal}

\subsection{1 Çimento}

Çalışmada CEM I 42,5 R tipi Portland Çimentosu kullanılmıştır. Yapılan deneyler sonucu çimentonun özgül ağırlığı $3,1 \mathrm{~g} / \mathrm{cm}^{3}$ ve özgül yüzeyi (Blaine) $3320 \mathrm{~g} / \mathrm{cm}^{2}$ olarak belirlenmiştir. Çimentonun Yozgat Votorantim Çimento Fabrikası tarafından belirlenen diğer fiziksel özelliklerine ve kimyasal bileşimine Taşkan (2017)'den erişilebilir.

Çizelge 1. Agregaların elek analizi ve fiziksel özelik değerleri.

\begin{tabular}{|c|c|c|c|c|c|c|c|c|c|c|}
\hline \multirow{2}{*}{ Agrega } & \multirow{2}{*}{$\begin{array}{c}\text { Özgül } \\
\text { ağırlık } \\
\left(\mathrm{g} / \mathrm{cm}^{3}\right)\end{array}$} & \multirow{2}{*}{$\begin{array}{c}\text { Su } \\
\text { emme } \\
(\%)\end{array}$} & \multicolumn{8}{|c|}{ Elek boyutu, $\mathrm{mm} \%$ Geçen } \\
\hline & & & 0,25 & 0,5 & 1 & 2 & 4 & 8 & 16 & 32 \\
\hline İnce agrega (0-4) & 2,63 & 1,2 & 22,5 & 32,6 & 48,5 & 63,0 & 90,1 & 100 & 100 & 100 \\
\hline Kaba agrega (4-12) & 2,70 & 0,5 & 0,3 & 0,3 & 0,3 & 0,3 & 3,3 & 74,5 & 100 & 100 \\
\hline Kaba agrega (12-25) & 2,71 & 0,4 & 0,2 & 0,2 & 0,2 & 0,2 & 0,4 & 0,8 & 14,8 & 100 \\
\hline
\end{tabular}

\subsubsection{Agrega}

Çalışma kapsamında kalker esaslı agregalar kullanılmıştır. Agregaların elek analizi sonuçları ve özgül ağırlık ve su emme değerleri Çizelge 1'de sunulmaktadır.

\subsubsection{Kimyasal Katkı}

Çalışma kapsamında polikarboksilik eter esaslı yüksek oranda su azaltıcı özellikte ikinci nesil süperakışkanlaştırıcı kimyasal katkı kullanılmıştır.

\subsection{4 Çelik Tel}

Çalışmada, narinlikleri aynı kanca ucu tipleri ve kanca boyları farklı olan 3 farklı çelik tel kullanılmıştır. Çelik tellere ait özelikler Çizelge 2'de ve görüntüler Şekil 1'de sunulmaktadır. 
Çizelge 2. Çelik tellerin özelikleri.

\begin{tabular}{|c|c|c|c|c|c|}
\hline $\begin{array}{l}\text { Çelik Tel } \\
\text { Tipi }\end{array}$ & $\begin{array}{c}\text { Boy, } \\
\text { I } \\
(\mathrm{mm})\end{array}$ & $\begin{array}{c}\text { Çap, } \\
\text { d } \\
(\mathrm{mm})\end{array}$ & $\begin{array}{c}\text { Narinlik, } \\
\text { (1/d) } \\
\text { (uzunluk/çap) }\end{array}$ & $\begin{array}{c}\text { Yoğunluk, } \\
\delta \\
\left(\mathrm{g} / \mathrm{cm}^{3}\right)\end{array}$ & $\begin{array}{c}\text { Çekme } \\
\text { Dayanımı, } \\
\left(\mathrm{N} / \mathrm{mm}^{2}\right)\end{array}$ \\
\hline $3 \mathrm{D} 65 / 60 \mathrm{BN}$ & 60 & 0,90 & 65 & 7,85 & 1160 \\
\hline 4D 65/60 BG & 60 & 0,90 & 65 & 7,85 & 1500 \\
\hline $5 \mathrm{D} 65 / 60 \mathrm{BG}$ & 60 & 0,90 & 65 & 7,85 & 2300 \\
\hline
\end{tabular}

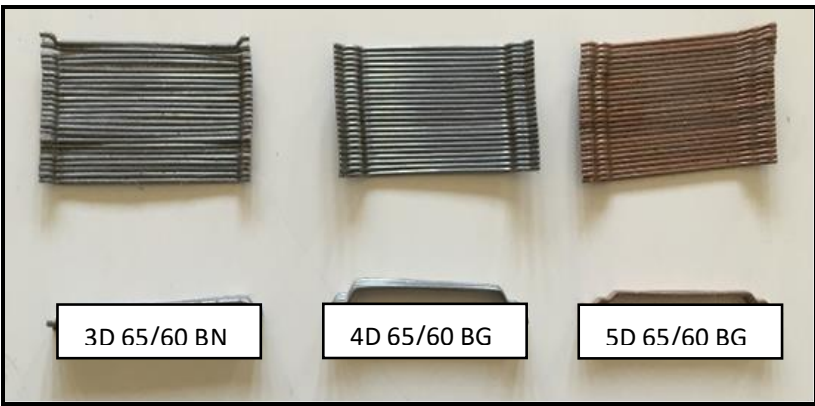

Şekil 1. Çelik teller.

Kullanılan çelik tellerin boy ve çapları dolayısıyla narinlikleri aynı seçilmiştir. Bununla birlikte, tellerin kanca uçları ve dayanımları farklılık göstermektedir. Kanca ucu boylarına göre teller 3D, 4D ve 5D olarak sınıflandırılmıştır.

\subsection{Karışımlar}

Farklı kanca ucu tipine sahip tellerin betonlara farklı miktarlarda $\left(15 \mathrm{~kg} / \mathrm{m}^{3}-60 \mathrm{~kg} / \mathrm{m}^{3}\right)$ katılmasıyla karışımlar oluşturulmuştur. Karışımlarda artan çelik tel miktarı için agrega miktarları değiştirilmişsir. Çimento ve su miktarları dolayısıyla su/çimento oranı sabit tutularak betonlarda su/çimento oranından dolayı oluşabilecek dayanım farklılıkları engellenmiştir. Beton bileşenleri ve karışım miktarları Çizelge 3'te verilmektedir. Karşımlar tel tipi ve miktarı dikkate alınarak kodlanmıştır. Örneğin; 3DV15 3D kanca ucu tipine sahip telin 15 $\mathrm{kg} / \mathrm{m}^{3} \quad$ miktarında kullanıldığı karışımı göstermektedir.

Çizelge 3. Beton bileşenleri ve karışım miktarları $\left(\mathrm{kg} / \mathrm{m}^{3}\right)$.

\begin{tabular}{|c|c|c|c|c|c|c|}
\hline $\begin{array}{l}\text { Tel } \\
\text { Miktarı }\end{array}$ & Çimento & $\mathrm{Su}$ & $\begin{array}{c}\text { Ince } \\
\text { Agrega } \\
(0-4)\end{array}$ & $\begin{array}{c}\text { Kaba } \\
\text { Agrega } \\
(4-12)\end{array}$ & $\begin{array}{c}\text { Kaba } \\
\text { Agrega } \\
(12-25)\end{array}$ & $\mathrm{SA}^{*}$ \\
\hline 0 & & & 892 & 515 & 479 & \\
\hline 15 & & & 890 & 514 & 478 & \\
\hline 30 & 300 & 180 & 887 & 512 & 476 & 2,0 \\
\hline 45 & & & 885 & 511 & 475 & \\
\hline 60 & & & 883 & 510 & 474 & \\
\hline
\end{tabular}

*SA: Süperakışkanlaştırıcı

\subsection{Metotlar}

\subsubsection{Beton Deney ve Standartları}

Çalışma kapsamında yürütülen geleneksel beton deneyleri ve standartları Çizelge 4'te sunulmaktadır.

Çizelge 4. Geleneksel beton deneyleri ve standartları.

\begin{tabular}{ll}
\hline Deney Adı & Standart \\
\hline Çökme & TS EN 12350-2 \\
\hline Vebe & TS EN 12350-3 \\
\hline Birim Ağırlık (Taze beton) & TS EN 12350-6 \\
\hline Birim Ağırlık (Sertleşmiş beton) & TS EN 12390-7 \\
\hline Basınç Dayanımı & TS EN 12390-3 \\
\hline Yarmada Çekme Dayanımı & TS EN 12390-6 \\
\hline Eğilmede Çekme Dayanımı & TS EN 14651 \\
\hline
\end{tabular}

\subsubsection{Eğilmede Çekme Dayanımı Tayini}

Eğilmede çekme dayanımı tayini deneyi ASTM C 1609 standardına uygun olarak yapılmıştır. Numunelerin genişlik ve yüksekliği 150'şer mm, uzunluğu $550 \mathrm{~mm}$ ve mesnet açıklığı $450 \mathrm{~mm}$ 'dir. Yükleme Şekil 2'de gösterilmektedir.

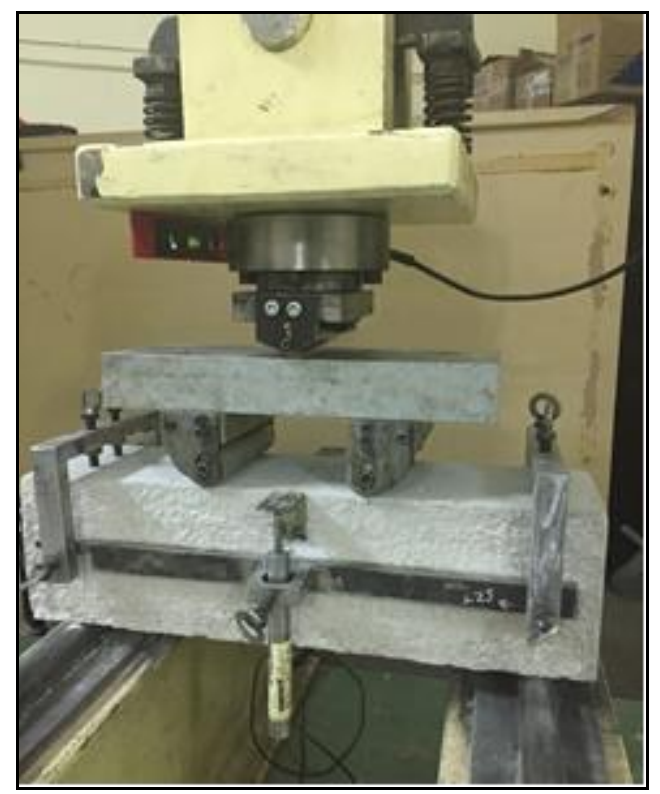

Şekil 2. Yükleme düzeneği.

Hesaplamalar:

Eğilme dayanımı:

$$
f=\frac{P L}{b d^{2}}
$$

Burada;

$f$, eğilme dayanımı $\left(\mathrm{N} / \mathrm{mm}^{2}\right), P$, yük değeri $(\mathrm{N}), \mathrm{L}$, 
mesnetler arası açıklık (mm), $b$, numunenin genişlik $(\mathrm{mm})$ ve $d$, numunenin yükseklik $(\mathrm{mm})$ değerlerini göstermektedir.

Eşdeğer eğilme gerilme oranı:

$$
R_{T_{2}, 150}^{D}=\frac{150 * T_{150}^{D}}{f_{1} b d^{2}} * 100(\%)
$$

Burada;

$R_{T, 150}^{D}:$ Eşdeğer eğilme gerilme oranı, \%

$T_{150}^{D} \quad$ : Tokluk, Joule (N.m)

$f_{1} \quad$ : ilk-tepe dayanımı, MPa

Formüldeki 150 değeri L/150'yi ifade etmek için kullanılmaktadır. Bu çalışmada L, $450 \mathrm{~mm}$ 'dir. Dolayısıyla, L/150=3mm sehime kadar yükleme yapılmıştır. Tokluk değerleri yük-sehim eğrisi altındaki alandan hesaplanmıştır.

\section{Bulgular}

\subsection{Taze Beton Deney Sonuçları}

Çelik tel donatılı betonların işlenebilirliği genellikle Vebe deneyi ile değerlendirilmektedir (Şekil 3). Çalışma kapsamında yürütülen diğer taze beton deneylerine ait sonuçlara Taşkan (2017)'den ulaşılabilir.

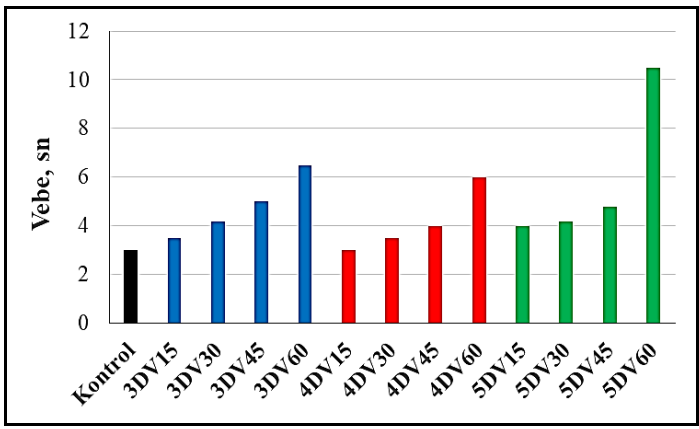

Şekil 3. Vebe deneyi sonuçları.

Çelik tellerin kullanılmadığı kontrol karışımının Vebe sınıfı V4 (3-5 sn) olarak elde edilmiştir. Tellerin ilave edilmesiyle betonların Vebe sürelerinde artış görülmüştür. Tel içeriği yüksek olan $\left(60 \mathrm{~kg} / \mathrm{m}^{3}\right)$ betonlarda Vebe sürelerinin arttığı ve V3 (6-10 sn) sınıfında yer aldığı belirlenmiştir. Vebe süreleri üzerinde telin kanca ucu tipi özeliklerinin belirgin bir etkisi görülmemiştir.

\subsection{Sertleşmiş Beton Deney Sonuçları}

\subsubsection{Basınç Dayanımı ve Elastisite Modülü}

Betonlar üzerinde yapılan basınç deneyi sonuçlarına göre beton basınç dayanım sınıfının C40/50 (TS EN 206) olduğu görülmüştür. Betonların elastisite modülleri ise $30 \mathrm{GPa}$ olarak elde edilmiştir. Betonların basınç dayanımları ve elastisite modülleri üzerinde tel miktarının ve kanca ucu tipinin belirgin bir etkisinin olmadığ görülmüştür. Basınç dayanımı ve elastisite modülü sonuçları sırasıyla Şekil 4 ve Şekil 5'te verilmektedir.

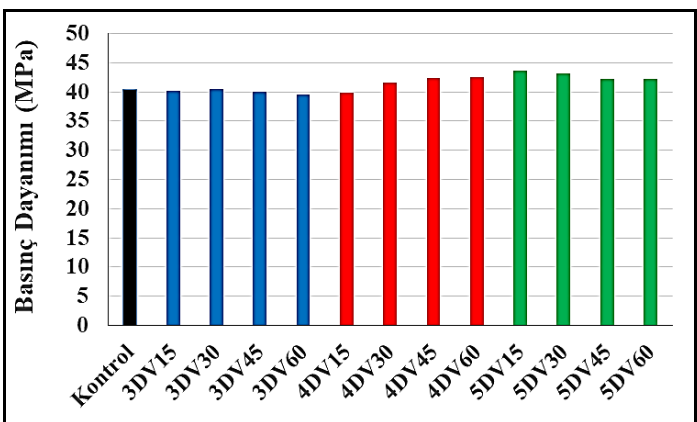

Şekil 4. Basınç dayanımı sonuçları.

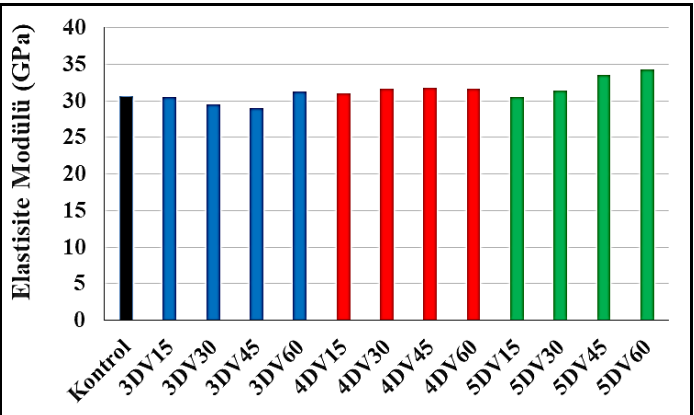

Şekil 5. Elastisite modülü sonuçları.

\subsubsection{Yarmada Çekme Dayanımı}

Betonlara çelik tel ilave edilmesiyle yarmada çekme dayanımlarında belirgin artışlar görülmüştür. Karışımların, tel içermeyen kontrol karışımına kıyasla yarmada çekme dayanımını artırdığı miktarlar her bir çubuğun üzerinde yüzde (\%) olarak belirtilmiştir. 


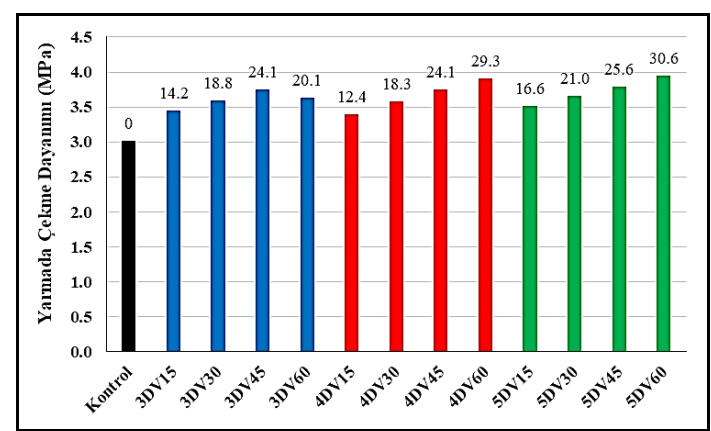

Şekil 6. Yarmada çekme dayanımı sonuçları.

Tel miktarının artmasıyla tüm kanca ucu tipleri için yarmada çekme dayanımlarının arttığı belirlenmiştir.

\subsubsection{Eğilme dayanımı}

Çalışmada uygulanan eğilme deneyi Madde 2.3.2' de açıklanmıştır. Deney sonuçları Çizelge 5'te verilmektedir. Eğilme dayanımı ve eşdeğer eğilme gerilme oranı değerlerinin hesaplanmasında kullanılan yük sehim eğrileri Şekil 7'de verilmektedir.

Çizelge 5. Eğilme deneyi sonucu elde edilen değerler.

\begin{tabular}{lcccc}
\hline $\begin{array}{l}\text { Karışım } \\
\text { kodu }\end{array}$ & $\begin{array}{c}\mathbf{P} \\
\mathbf{k N}\end{array}$ & $\begin{array}{c}\boldsymbol{f} \\
\mathbf{M P a}\end{array}$ & $\begin{array}{c}\boldsymbol{T}_{\mathbf{1 5 0}}^{\mathrm{D}} \\
\mathbf{N m}\end{array}$ & $\begin{array}{c}\boldsymbol{R}_{\tau_{1}, 150}^{D} \\
\mathbf{\%}\end{array}$ \\
\hline Kontrol & 27,00 & 3,60 & - & - \\
3DV15 & 29,40 & 3,93 & 24,9 & 28,0 \\
3DV30 & 27,40 & 3,65 & 48,1 & 60,0 \\
3DV45 & 30,75 & 4,11 & 71,1 & 79,0 \\
3DV60 & 34,00 & 4,54 & 86,2 & 109,0 \\
4DV15 & 29,25 & 4,19 & 39,2 & 44,0 \\
4DV30 & 28,70 & 3,82 & 54,1 & 63,0 \\
4DV45 & 32,90 & 4,39 & 70,7 & 79,5 \\
4DV60 & 39,60 & 5,28 & 106,5 & 120,0 \\
5DV15 & 28,50 & 3,81 & 38,8 & 45,5 \\
5DV30 & 29,55 & 3,94 & 47,6 & 54,5 \\
5DV45 & 28,90 & 3,85 & 62,7 & 72,5 \\
5DV60 & 46,40 & 6,19 & 109,6 & 113,0 \\
\hline
\end{tabular}

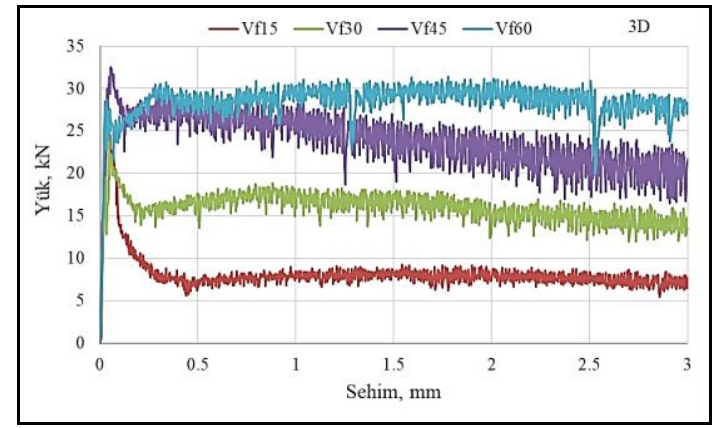

(a) 3D kanca uçlu teller

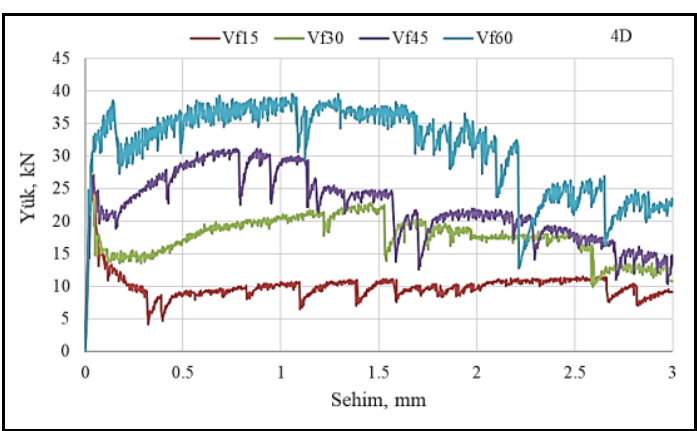

(b) 4D kanca uçlu teller

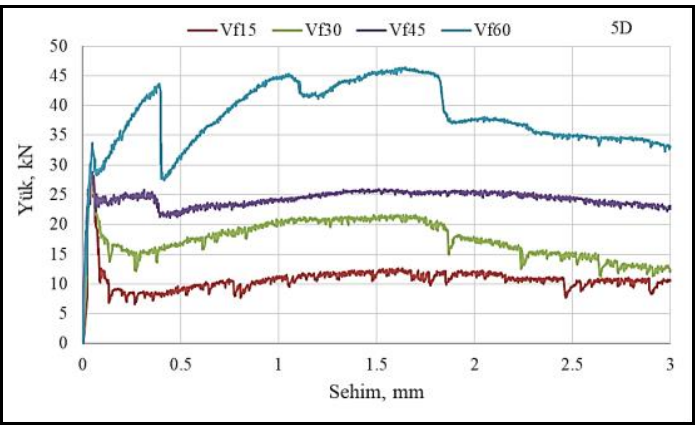

(c) 5D kanca uçlu teller

Şekil 7. Yük-sehim eğrileri-Tel miktarı etkisi.

Şekil 7'de sunulan yük-sehim eğrilerinden lif miktarının artmasıyla tüm kanca tipleri için eğri altında kalan alanları arttığı görülebilmektedir. Kanca tipi etkisi için düşük ve yüksek tel içeriklerine ait grafikleri Şekil 8'de sunulmaktadır.

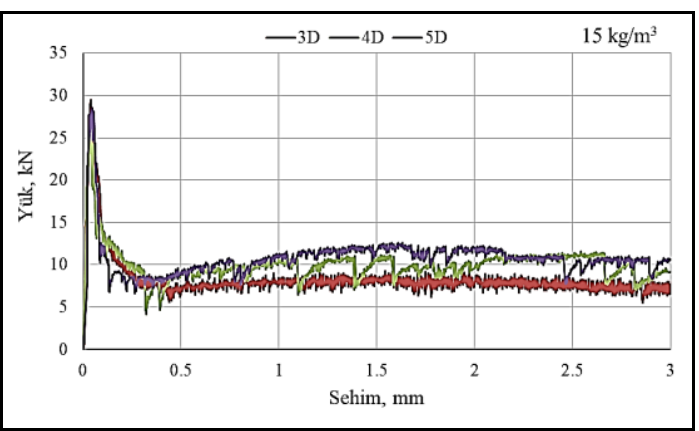

(a) $V_{f}=15 \mathrm{~kg} / \mathrm{m}^{3}$

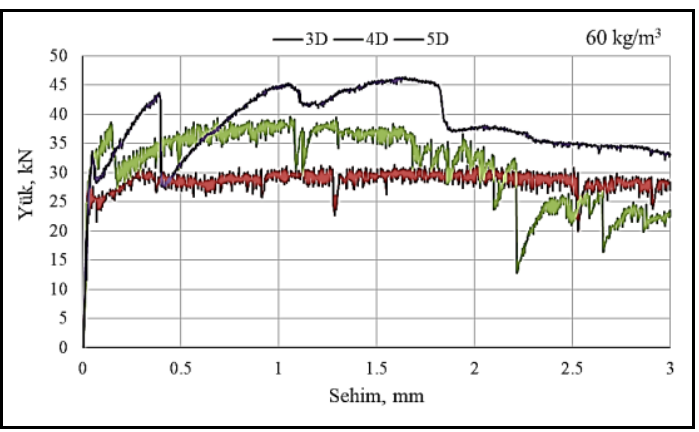

(b) $V_{\mathrm{f}}=60 \mathrm{~kg} / \mathrm{m}^{3}$

Şekil 8. Yük-sehim eğrileri-Kanca tipi etkisi. 
Eğilme dayanımı değerlerine ait grafikler Şekil 9'da verilmektedir. Karışımların, tel içermeyen kontrol karışımına kıyasla eğilmede çekme dayanımını artırdığı miktarlar her bir çubuğun üzerinde yüzde (\%) olarak belirtilmiştir.

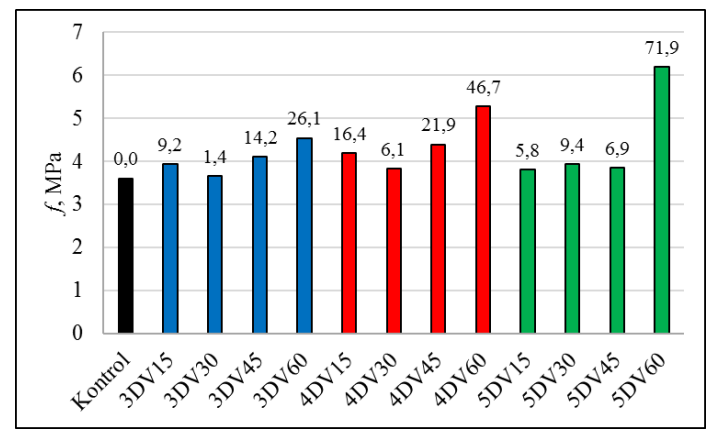

Şekil 9. Eğilme dayanımı değerleri.

Şekil 9 incelendiğinde tel kanca tipinin eğilme dayanımı değerleri üzerinde belirgin bir etkisinin olmadığı bununla birlikte tel miktarının artmasıyla eğilme dayanımı değerlerinin arttığı söylenebilir.

Yük sehim eğrileri altından kalan alandan hesaplanan tokluk değerlerine ve tokluk değerleri kullanılarak hesaplanan eşdeğer eğilme gerilme oranı değerlerine ait çubuk grafikler sırasıyla Şekil 10 ve Şekil 11 'de sunulmaktadır. Karışımların, tel içermeyen kontrol karışımına değerleri artırdığı miktarlar her bir çubuğun üzerinde yüzde (\%) olarak belirtilmiştir.

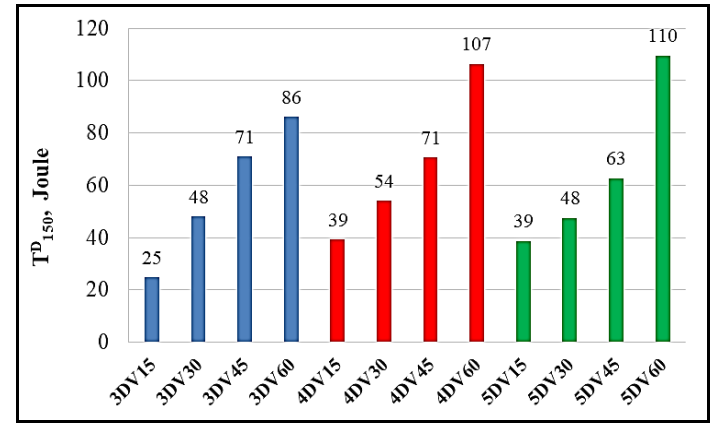

Şekil 10. Tokluk değerleri.

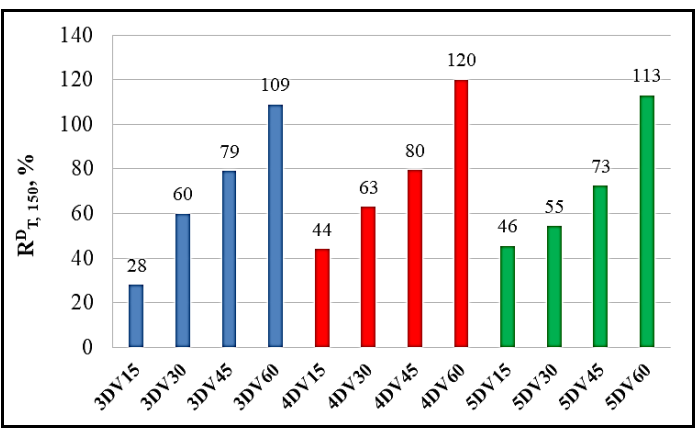

Şekil 11. Eşdeğer eğilme gerilme oranı değerleri.

Tokluk değerleri ve eşdeğer eğilme gerilme oranı değerleri üzerinde tel miktarının etkisi belirgin olarak gözlenmekte ve tel miktarı arttıkça bu değerlerin arttığı görülmektedir. Tel kanca tipinin etkisi düşük $\left(15 \mathrm{~kg} / \mathrm{m}^{3}\right)$ tel miktarlarında, 3D'den 5D kanca tipine gidildikçe yani kancanın kıvrımı arttıkça, tokluk ve eşdeğer eğilme gerilme oranı değerleri artmıştır. Karışımlarda kullanılan tel miktarının artmasıyla 5D kanca tipinin etkisi azalmış ve daha düşük değerler elde edilmiştir. Bu duruma neden olarak kanca ucundan dolayı tellerin beton içerisinde iyi dağılamamış olması düşünülebilir.

\section{Tartışma ve Sonuç}

Çalışmada ulaşılan bulguların değerlendirmeleri aşağıda sıralanmaktadır.

Taze beton özelikleri üzerinde çelik tel kanca ucu tipinin belirgin bir etkisi görülmemiştir. Fakat, tel içeriğinin artmasıyla betonların işlenebilirlik özelikleri olumsuz etkilemiştir.

Betonların basınç dayanımları ve elastisite modülleri üzerinde çelik tellerin kanca ucu tipi ve miktarının belirgin bir etkisi görülmemiştir.

Çelik tellerin ilave edilmesiyle betonların yarmada çekme dayanımlarında artışlar görülmüştür. Yarmada çekme dayanımı üzerinde tel kanca ucu tipinin etkisi görülmüş ve $5 D$ tipi tellerin kullanılmasıyla kontrol karışımına kıyasla \%30 civarında artışlar elde edilmiştir. 3D'den 5D kanca tipine gidildikçe yani kancanın kıvrım boyu arttıkça yarmada çekme dayanımlarında daha yüksek artışlar elde edilmiştir. 
Çelik tel miktarı ve kanca tipi etkisi yük-sehim eğrilerinde belirgin olarak görülmektedir. Tel miktarı artmasıyla eğri altında kalan alan artmıştır. Genel olarak çelik tel kanca boyu eğri altında kalan alan üzerinde etkili olmuştur. Kanca boyunun en fazla olduğu 5D kanca tipinin en etkili çelik tel olduğu görülmüştür.

ÇTDB'lerin yük-sehim eğrilerinde görüldüğg̈ü gibi ilk çatlak sonrası numuneler yük taşımaya devam etmiştir. Eğrilerde görülen yüklemenin ani düşüşleri çelik tellerin kopması sonucunda oluştuğu söylenebilir.

Tokluk ve eşdeğer eğilme gerilme oranları incelendiğinde tel kanca ucu tipinin etkisinin tel miktarına göre değişiklik gösterdiği görülmüştür. Düşük tel miktarlarında kanca boyu en fazla olan 5D kanca ucu tipine sahip teller daha yüksek performans sergilerken, tel miktarının artmasıyla bu etkileri azalmıştır. Elde edilen bu sonuç ışığında, optimum tokluk ve eşdeğer eğilme gerilme oranı değerlerinin tel miktarı ve tel kanca tipine bağlı olarak belirlenebileceği görülmüştür.

Çalışmada, çelik tel kanca ucu tipinin etkisi üzerine odaklanılmış ve uygun çelik teller seçilerek uzunluk, narinlik gibi diğer etkiler ortadan kaldırılmıştır. Bununla beraber, tellerin çekme dayanımlarının etkisi, düşük beton dayanımı seçilerek böylece tellerin beton matrisinden kopma yerine sıyrıması sağlanarak azaltılmaya çalışılmıştır. Kanca ucu tipleri farklı çekme dayanımları aynı olan tellerin farklı dayanımlara sahip betonlarda kullanılması ve etkilerinin araştırıması sonraki çalışmalara konu olabilecektir.

\section{Teşekkür}

Bu çalışma Yozgat Bozok Üniversitesi Proje Koordinasyon Araştırma ve Uygulama Merkezi tarafından desteklenmiştir (Proje no: 2015FBE/T213).

\section{Kaynaklar}

Altun, F., Haktanır, T., Arı, K., 2007. Effects of steel fiber addition in mechanical properties of concrete and RC beams. Construction and Building Materials, 21, 654661.
Banthia, N., Trottier, J., 1994. Concrete reinforced with deformed steel fibers, part I: bond-slip mechanisms. ACI Materials Journal, 91, 435-446.

Beddar, M., 2004. Fibre-Reinforced concrete - past, present and future. Concrete, ABI/INFORM Trade \& Industry, April, 47-49.

Boğa, A.R., 2017. Harçların mekanik ve elektriksel iletkenlik özelliklerine karbon lifi ve çelikhane cürufu kullanımının etkisi. Afyon Kocatepe Üniversitesi Fen ve Mühendislik Bilimleri Dergisi, 17, 1066-1075.

Cunha, V.M.C.F., Barros, J.A.O., Sena-Cruz, J.M., 2010. Pullout behavior of steel fibers in self-compacting concrete. Journal of Materials in Civil Engineering, 22 1, 1-9.

Feng, J., Sun, W.W., Wang, X.M., Shi, X.Y., 2014 Mechanical analyses of hooked fiber pullout performance in ultra-high-performance concrete. Construction and Building Materials, 69, 403-410.

Gündüz Y., 2015. Çelik tel donatılı betonlarda kırılma parametrelerinin yapay sinir ağları ile modellenmesi. Yüksek lisans tezi, Bozok Üniversitesi Fen Bilimleri Enstitüsü, Yozgat,136.

Knapton, J., 2003. Ground bearing concrete slabs. Thomas Telford, London.

Pajak, M., Ponikiewski, T. 2017. Investigation on Concrete Reinforced with Two Types of Hooked Fibers under Flexure. Procedia Engineering, 193, 128135.

Robins, P., Austin, S., Jones, P., 2002. Pull-out behaviour of hooked steel fibres. Materials and Structures, 35 251, 434-442.

Soetens, T., Matthys, S., 2014. Different methods to model the post-cracking behaviour of hooked-end steel fibre reinforced concrete. Construction and Building Materials, 73, 458-471.

Taşdemir, M.A., Bayramov, F., 2002. Yüksek performanslı çimento esaslı kompositlerin mekanik Davranışı. Itü dergisi/d, 1, 2, 125-144.

Taşdemir, M.A., Şengül, Ö., Şamhal, E., ve Yerlikaya, M., 2006. Endüstriyel zemin betonları. İnşaat Mühendisleri Odası İstanbul Şubesi, İstanbul. 
Taşkan E., 2017. Çelik tel kanca tipinin betonların mekanik özelliklerine etkisi. Yüksek lisans tezi, Bozok Üniversitesi Fen Bilimleri Enstitüsü, Yozgat, 122.

Uğur A., 2015. Çelik lif uç geometrisinin beton özelliklerine etkisi, Yüksek lisans tezi. İstanbul Teknik Üniversitesi Fen Bilimleri Enstitüsü, İstanbul.

Yoo, D. Y., Shin, H. O., Yang, J. M., Yoon, Y. S., 2014 Material and bond properties of ultra high performance fiber reinforced concrete with micro steel fibers. Composites Part B: Engineering, 58, 122133. 